\title{
Motivation and learner variables: Group differences in college foreign language learners' motivations
}

\author{
Sung, Ko-Yin \\ Utah State University, USA (koyin.sung@usu.edu) \\ Tsai, Hsiao-Mei \\ Utah State University, USA (disappear9541@gmail.com)
}

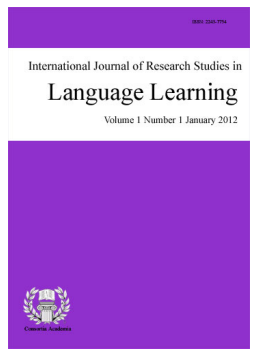

ISSN: 2243-7754 Online ISSN: 2243-7762

OPEN ACCESS

\section{Abstract}

In this study, the researchers surveyed 130 language learners enrolled in first-year foreign language classrooms in a public university in Utah, United States. This study intended to address the following research questions: (1) What motivational factors are found among learners enrolled in first-year foreign language courses at the university level in the United States?, (2) Do first-year language learners' motivations differ based on the following learner variables: (a) gender, (b) language being learned, (c) major, and (d) religion? and (3) What motivational factors predict learners' interest in continuing foreign language learning? Factor analysis, MANOVA, and multiple regressions were run to answer the questions. The factor analysis results found seven motivational factors: positive learning attitudes/experience and intended efforts, interest in culture, travel, and people, interest in contemporary cultural media, milieu, instrumentality, language requirement, and religion. The MANOVA results showed that major and religion had significant effects on motivation. The results of the multiple regression test indicated that two motivational factors, positive learning attitudes/experience and intended efforts, and interest in culture, travel, and people, predicted the participants' interest in future L2 study.

Keywords: language learning motivation; religion; major; college learners; survey study 


\section{Motivation and learner variables: Group differences in college foreign language learners' motivations}

\section{Introduction}

The newest results of the surveys of foreign language enrollments in United States institutions of higher education conducted by Furman, Goldberg, and Lusin (2010) of Modern Language Association (MLA) reported a record high in foreign language course enrollments. There were more than 1.6 million students enrolled in foreign language courses at college level in the United States in 2009, which was $8.6 \%$ of the US college total enrollments. In addition, the survey results showed a continuous rise in foreign language enrollments since 1995. As the number of students in foreign language courses grows continuously, it would be useful to learn students' motives for learning a foreign language in order to create a curriculum which will help them succeed. Research has shown that language teachers often do not learn their students' specific motivations for studying a language and do not account for their motivations when designing classroom activities (Geisherik, 2004). Hence, one purpose of this study was to explore students' motivations in taking foreign language classes. In addition to finding the different dimensions of motivations learners possessed, this study intended to examine motivational differences in different groups of students, which would provide a more varied understanding of how to motivate and sustain the motivational level of particular groups of students. The learner variables examined in this study include gender, language being learned, major, and religion. The literature review section of this study justified the importance of examining the four variables mentioned above. Finally, the MLA survey results indicated that the introductory language courses accounted for the majority percentages of the foreign language enrollments while the intermediate and advanced course enrollments only accounted for $16.7 \%$ of the total enrollments. In order to sustain students' motivation levels to continue the language study and maximize their learning results, identifying the motives related to the desire to continue language study would be necessary. Hence, this study attempted to find what specific motivations would predict first-year learners' interest in continuing foreign language learning.

\section{Literature review}

\subsection{L2 motivation}

Among the many individual learner variables, motivation is considered one of the primary factors in predicating learners' success in learning a second language (Gardner \& Lalonde, 1985). As Dörnyei and Csizér (1998) phrased it, 'Without sufficient motivation, even individuals with the most remarkable abilities cannot accomplish long-term goals, and neither are appropriate curricular and good teaching enough to ensure student achievement' (p. 203). Motivation, an affective factor, is defined by Gardner and Lalonde (1985) as 'the desire (or wanting) to learn the language, the motivational intensity (or effort expended) to learn the language, and the affective reactions (or attitudes) toward learning the language' (p. 5). In the past few decades, researchers made enormous efforts in research to understand the role of motivation in second language acquisition. One of the most influential works is the socio-educational model developed by Gardner and his associates (Gardner \& Lambert, 1972; Gardner, 1985). The model proposed two motivational orientations: integrative and instrumental. Integrative orientation is the desire to identify with the target language speakers and instrumental orientation refers to the practical reasons for studying the target language such as passing an examination or advancing a career. Both motivational orientations have been reported as significant factors influencing language learning success (Wen, 2011).

With the intention to call for alternative and potentially new interpretations of language learning motivation, 
Motivation and learner variables: Group differences in college foreign language learners' motivations

Dörnyei (2005) integrated Gardner's (1985) model and Higgins's (1987) self-discrepancy theory to develop the L2 Motivational Self System, which consists of three main components: Ideal L2 Self, Ought-to L2 Self, and L2 Learning Experience. The first component, Ideal L2 Self, is similar to the integrative motivation identified by Gardner (1985), which refers to the learner's wish to master the L2 as his or her ideal self-image and is the primary constituent of L2 motivation. The second component, Ought-to L2 Self, refers to extrinsic types of instrumental motives. It represents attributes that one believes one ought to possess in order to avoid any negative outcomes. The major distinction between the Ideal and the Ought-to L2 Selves is that the former has a promotion focus (e.g. hopes, growth, and accomplishments) while the latter has a prevention focus (e.g. safety, responsibilities, and obligations) (Csizér \& Dörnyei, 2005). The third component, L2 Learning Experience, is related to the learners' learning environment and experience. In a large-scale motivational study conducted by Dörnyei, Csizér, and Németh (2006) in Hungary from 1993 to 2004, Dörnyei identified several motivational dimensions. They include integrativeness, instrumentality, attitudes towards the L2 speakers/community, milieu, linguistic self-confidence, cultural interest, and ethnolinguistic vitality. These motivational constituents are the major motivational dimensions commonly found in past L2 motivation research.

The framework of this study is based on Gardner's (1985) and Dörnyei's (2005) models. Both have been widely used and proved to be robust in interpreting results in other motivation studies (Gholam-Reza, Babak, \& Reza, 2013). Hence, the adoption of these two scholars' models of motivation would present a comprehensive picture of motivational dimensions.

\subsection{L2 motivation and learner variables}

This study examined whether there were motivational differences in the following learner variables: gender, language being learned, major, and religion. A review of the current literature indicated that the variable, gender, is often found to be a significant variable in motivation. Many studies reported the superiority of female learners in L2 motivation over male learners and that male and female learners possess different types of L2 motivation (Ghazvini \& Khajehpour, 2011; Henry, 2010; Mori \& Gobel, 2006; Sung \& Padilla, 1998; Williams, Burden, \& Lanvers, 2002). Only few studies (Al-Bustan \& Al-Bustan, 2009; Polat, 2011) showed opposite results. For example, Polat's (2011) study on middle and high school Kurdish learners of Turkish reported the superiority of the male participants in two motivational orientations (identification and integrated orientations) over the female participants. These two motivational orientations were defined by Polat (2011) as demonstrating 'more autonomy in determining and manipulating their own actions' (p. 21). Another study which showed higher motivation of males over females is Al-Bustan and Al-Bustan's (2009) research on Kuwaiti learners of English. The researchers reported a relationship between the negative past high school English learning with the negative attitude of female students towards learning English. Interestingly, such negative attitudes were not found within the male sample population in the study. The inconsistent findings of gender in motivation imply that more research in the gender variable is needed to offer more insights towards the current literature.

The rest of the variables, language being learned, major, and religion, is rarely investigated in current literature. With respect to the variable, language being learned, most motivation studies only focused on a single language. Studies which compared learners studying different languages, such as Csizér and Kormos's (2008), are few and far between. Csizér and Kormos (2008) compared the motivations of two groups of Hungarian learners; one studying English and the other studying German. The study had a few findings. First, the learners of English had a more positive attitude towards the native speakers of the language they studied than the learners of German. Second, the learners of English had higher levels of self-confidence in learning a language, made more efforts in studying the language, and received more support from their environment than the learners of German. Csizér and Kormos (2008) suspected that the fact that English, which is the global language, has a higher level of ethnolinguistic vitality than German may have contributed to the motivational differences between the Hungarian learners of German and English. With the variable, language being learned, the current study compared learners of two groups of languages: commonly taught languages (CTL) and less commonly taught languages (LCTL). CTL such as French, German, and Spanish have been maintaining high enrollments 
and many of the LCTL are identified as critical languages by the US government and have seen increasing enrollment in recent years. It would be interesting to see whether the current ethnolinguistic climates of these languages in the United States create differences in learner motivation.

With regard to the variable, major, a motivation study conducted by Tong and Shi (2012) reported positive motivation toward English language learning of undergraduate science majors in southeast China. The researchers explained that science major was considered by the Chinese Ministry of Education as one of the most important disciplines to prioritize Chinese-English bilingual education. It could be this educational policy in China that positively influenced the learners' motivations. The current study included the variable, major, to see whether different expectations or views of different majors would result in motivational differences.

To the best of the researchers' knowledge, the literature on motivation and religion is almost non-existent. The only study related to motivation and religion was conducted by Larson-Hall and Dewey (2012) on 44 English-speaking members of the Church of Christ of Latter-Day Saints (LDS). These learners were missionaries studying Japanese as a second language. A unique motivation found in the study is the learners' belief that they are blessed with the gift of tongues in learning languages. Larson-Hall and Dewey (2012) explained that the participants who had this unique motivation believed that 'God helps them to learn the language so that they can do His work' (p. 71). If the religion belief, specifically the LDS belief mentioned in the previous study, resulted in a specific motivation in the LDS learner group, the current study conducted in Utah with dense LDS population (62.4\% of Utah population) (Canham, 2005) should take into account the religion variable. Considering the lack of research on the relationship between religious beliefs and motivation in learning a language, findings regarding the LDS group's religious beliefs in relation to their language learning motivation in this study would make a significant contribution to the current literature.

Csizér and Dörnyei (2005) stated that learners' interest in pursuing future language study is mediated through motivational factors, which contribute to learners' language attainment; therefore, it would be important for this study to identify what motivational factors predict learners' choice for future language study. A study conducted by Wen (2011) identified that positive learning attitudes and experience was the motivational factor predicting the intended continuation of study in the future. More studies such as the current one are needed to confirm Wen's (2011) finding.

\subsection{Research questions}

Informed by the current literature on motivation and learner variables, and considering the backgrounds of the participants in this study, the current study attempted to answer the following research questions:

$>$ What motivational factors are found among learners enrolled in first-year foreign language courses at the university level in the United States?

> Do first-year language learners' motivations differ based on the following learner variables: (a) gender, (b) language being learned, (c) major, and (d) religion?

$>$ What motivational factors predict learners' interest in continuing foreign language learning?

\section{Methods}

\subsection{Participants}

The survey sample consisted of 130 learners enrolled in the first-year foreign language classes in an university in the state of Utah, United States. This study used a non-probability sample, which was the population to whom the researchers had easy access. With regard to the background information of the sample, there were 65 males and 65 females in this study, ranking in age from 18 to 71 years $(M=21, S D=8.35)$. 
Motivation and learner variables: Group differences in college foreign language learners' motivations

Seventy learners were enrolled in the LCTL classes and 60 learners were enrolled in the CTL classes. Twenty-seven learners were Business majors, while 68 learners were Liberal Arts and 35 learners were other majors. With respect to learners' religions, 65 learners were LDS, and 24 learners believed in other religions, while 41 learners did not have any religious beliefs. With regard to their first language, 121 learners were English as first language speakers and nine learners spoke a first language other than English. Relatively few students were taking the class as graduate students $(n=4)$ and students who are not in the undergraduate or graduate programs $(n=5)$. A large number of the participants were freshmen $(n=16)$, sophomores $(n=40)$, juniors $(\mathrm{n}=36)$, and seniors $(\mathrm{n}=28)$.

\subsection{Instrument}

This quantitative study adopted Wen's (2011) motivation questionnaire with minor revisions in order to fit the backgrounds of the participants in the current study. Wen's (2011) questionnaire was adopted in this study because the instrument, which was pilot-tested, was carefully designed with a high internal consistency of .87 . The validity of the instrument was achieved through the motivational items listed in the questionnaire, which addressed the motivation constructs discussed in Gardner's (1985) and Dörnyei's (2005) frameworks. Their frameworks covered all possible aspects of the underlying motivation variables one could find in the current literature and were the frameworks used in this study. In addition, modifying the instrument to fit the participants' backgrounds in this study increased the degree of the construct validity. The revised questionnaire has two sections. The first section intended to gather participants' demographic information and their level of interest in continuing to learn the foreign languages in the future. The second section contains 27 items measuring the participants' motivations to learn the foreign languages. As no heritage learners were included in this study, questions related to heritage learners in the original questionnaire were excluded. Instead, two motivation items related to religion were added. The three items in the first section regarding participants' interests in continuing their foreign language study and the 27 motivation items in the second section were placed on a five-point Likert scale from '1' being 'Strongly Disagree', to '5' being 'Strongly Agree'.

\subsection{Procedure}

The researchers administered the motivation questionnaires during February and March in 2013 to participants enrolled in first-year Arabic, Chinese, French, German, Japanese, Portuguese, and Spanish courses in a university in Utah, United States. Participants were informed that the study was confidential and participation was voluntary. It took the participants approximately 15 to 20 minutes to complete the questionnaires in class. Among the 138 questionnaires collected, 130 of them were used in the study. The eight questionnaires not used either had incomplete answers or the learner background did not fit (e.g. heritage learners) the current study.

\subsection{Methods of analysis}

The survey data was analyzed through SPSS statistical software. All the statistical tests run in this study had a minimum conventional level of significance, $p=.05$. In addition, the null hypothesis was assumed in the tests. For the first research question, 'What motivational factors are found among learners enrolled in first-year foreign language courses at the university level in the United States?', factor analysis was run to identify the participants' motivational constructs. In order to ensure the reliability of the survey instrument, the Cronbach's coefficient alphas were calculated for all 27 motivation items and for the items found in each factor identified in the factor analysis test. MANOVA was run to answer the second research question, 'Do first-year language learners' motivations differ based on the following learner variables: (a) gender, (b) language being learned, (c) major, and (d) religion? MANOVA was used due to its ability to reduce Type I error and to determine the effects of multiple independent variables on several dependent variables simultaneously (George \& Mallery, 2005). In this study, the dependent variables were the motivational factors found in the factor analysis test. The independent variables were gender, language being learned, major, and religion. The participants were divided in groups in the 
Sung, K.-Y. \& Tsai, H.-M.

following ways. The gender factor consisted of a male group and a female group. The language being learned factor consisted of a CTL and a LCTL group. The CTL group included learners of French, German, and Spanish. The LCTL group consisted of learners of Arabic, Chinese, Japanese, and Portuguese. The major factor had three subgroups: Business, Liberal Arts, and other majors. The religion factor consisted of LDS, other religions, and not religious groups. Table 1 illustrates the descriptive statistics of the divided groups for each factor.

Table 1

Descriptive statistics of the groups in the MANOVA test

\begin{tabular}{lllc}
\hline \multicolumn{1}{c}{ Learner Factors } & & $\mathrm{N}$ & $\%$ \\
\hline Gender & Male & 65 & $50 \%$ \\
& Female & 65 & $50 \%$ \\
\hline Languages & Less Commonly Taught Languages (LCTL) & 70 & $54 \%$ \\
& Commonly Taught Languages (CTL) & 60 & $46 \%$ \\
\hline Major & Business & 27 & $21 \%$ \\
& Liberal Arts & 68 & $52 \%$ \\
& Other Majors & 35 & $27 \%$ \\
\hline Religion & LDS & 65 & $50 \%$ \\
& Other Religions & 24 & $18 \%$ \\
& Not Religious & 41 & $32 \%$ \\
\hline
\end{tabular}

To answer the third research question; what motivational factors predict learners' interest in continuing foreign language learning, a multiple regression test was run. The criterion variable was learners' interest in continuing foreign language learning and the predictor variables were the motivational factors found in the factor analysis test.

\section{Results}

\subsection{Factor analysis}

Using SPSS, an analysis of internal consistency reliability of the 27 motivation items showed that the Cronbach's alpha was .86 with $F(129,26)=97.587, p<.000$ indicating that there was a good internal consistency of the items being assessed. Factor analysis was conducted to check if there was any multidimensionality within the 27 motivation items and to see which items might vary together. The Kaiser-Meyer-Olkin measure of sampling adequacy was 0.78 , which supported the factorability of these data. The significance level of Bartlett test of sphericity $=.000$ indicated that these data were acceptable for factor analysis. The output of factor analysis revealed eight factors with eigenvalues exceeding one. An inspection of the screeplot revealed that seven factors were on the steep portion of the graph. It was decided to retain these seven factors for further investigation. The Varimax rotation result showed that 26 items moderately or strongly loaded on one of the seven factors. The subsequent seven-component solution explained $69 \%$ of the variance, with Factor 1 contributing 28\%, Factor 2 contributing 9\%, Factor 3 contributing 8\%, Factor 4 contributing 7\%, Factor 5 contributing 6\%, Factor 6 contributing 5\%, and Factor 7 contributing 4\%. Following the factor analysis, the analysis of internal consistency reliability of each factor was conducted. Table 2 illustrates that the Cronbach's alpha in each factor ranges from 0.76 to 0.89 indicating fair to reliable degree of reliability.

As shown in Table 2, Factor 1, which included nine motivational items, was loaded heavily on positive learning attitudes/experience and intended efforts. According to Dörnyei and Otto (1998), positive learning attitudes/experience may be related to learning efforts, which represents learners' motivational engagement. The fact that both positive learning attitudes/experience and intended efforts are loaded in the same factor in this study supports Dörnyei and Otto's (1998) claim. 
Motivation and learner variables: Group differences in college foreign language learners' motivations

Table 2

Principal components analysis with varimax rotation of seven-factor solution for learners' motivations

\begin{tabular}{|c|c|c|c|c|}
\hline ( & $\begin{array}{l}\text { Item-total } \\
\text { correlation }\end{array}$ & $\begin{array}{l}\text { Factor } \\
\text { loading }\end{array}$ & $h^{2}$ & $\mathrm{M}(\mathrm{SD})$ \\
\hline \multicolumn{5}{|c|}{ Factor 1: Positive learning attitudes/experience and intended efforts (Cronbach's alpha $=.89$ ) } \\
\hline $\begin{array}{l}\text { 24. I am active and interactive in my [target language] class } \\
\text { participation. }\end{array}$ & .754 & .819 & .765 & $4.38(.82)$ \\
\hline 27. I make good efforts to improve my [target language] skills. & .684 & .802 & .738 & $4.62(.61)$ \\
\hline $\begin{array}{l}\text { 20. I appreciate opportunities to speak [target language] with } \\
\text { my classmates. }\end{array}$ & .771 & .712 & .748 & $4.10(1.02)$ \\
\hline $\begin{array}{l}25 . \text { I try to use [target language] outside my [target language] } \\
\text { class with my classmates and friends }\end{array}$ & 690 & .709 & 699 & $4.18(.98)$ \\
\hline 21. I enjoy communicative activities in class. & 691 & 657 & .763 & $4.04(1.06)$ \\
\hline $\begin{array}{l}\text { 26. I do not give up on my course assignments before I } \\
\text { complete them. }\end{array}$ & .466 & .632 & .732 & $4.38(0.82)$ \\
\hline 19. It is fun to learn [target language]. & .696 & .626 & .676 & $4.38(.87)$ \\
\hline $\begin{array}{l}\text { 23. I think about the words and ideas that I have learned in my } \\
\text { [target language] class. }\end{array}$ & .534 & .582 & .444 & $4.35(.82)$ \\
\hline $\begin{array}{l}\text { 22. I like grammar explanations and exercises offered in the } \\
\text { curriculum. }\end{array}$ & .533 & .544 & .433 & 4.02(.97) \\
\hline \multicolumn{5}{|c|}{ Factor 2: Interest in culture, travel, and people (Cronbach's alpha $=.79)$} \\
\hline $\begin{array}{l}\text { 5. I want to visit a country where the [target language] is } \\
\text { spoken. }\end{array}$ & .695 & .688 & .634 & $4.48(.86)$ \\
\hline $\begin{array}{l}\text { 4. I am taking [target language] so that I will be able to meet } \\
\text { and converse with more [target language] people. }\end{array}$ & .603 & .685 & .656 & $4.37(.84)$ \\
\hline $\begin{array}{l}\text { 1. I want to use [target language] when I travel to a [target } \\
\text { language] speaking country. }\end{array}$ & .687 & .653 & .664 & $4.40(.96)$ \\
\hline $\begin{array}{l}\text { 12. I am taking [target language] so that I will be able to better } \\
\text { understand and appreciate [target language] culture. }\end{array}$ & .442 & .591 & .601 & $4.19(.89)$ \\
\hline \multicolumn{5}{|c|}{ Factor 3: Interest in contemporary cultural media (Cronbach's alpha $=.88)$} \\
\hline 17. I like to watch [target language] TV programs. & .794 & .896 & .858 & $2.52(1.28)$ \\
\hline 15. I like to watch [target language] films. & .768 & .878 & .822 & $2.69(1.27)$ \\
\hline 16. I like [target language] pop music and songs. & .730 & .795 & .741 & $2.85(1.33)$ \\
\hline \multicolumn{5}{|l|}{ Factor 4: Milieu (Cronbach's alpha $=.81)$} \\
\hline 7. People around me think it is good to learn [target language] & .734 & .841 & .857 & $2.89(1.22)$ \\
\hline $\begin{array}{l}\text { 6. I feel that my friends support me in learning [target } \\
\text { language]. }\end{array}$ & .647 & .833 & .776 & $3.05(1.27)$ \\
\hline $\begin{array}{l}\text { 8. My parents or relatives encourage me to learn [target } \\
\text { language]. }\end{array}$ & .599 & .797 & .761 & $2.9(1.27)$ \\
\hline \multicolumn{5}{|l|}{ Factor 5: Instrumentality (Cronbach's alpha $=.79)$} \\
\hline $\begin{array}{l}\text { 2. I think that [target language] will someday be useful in } \\
\text { getting me a good job. }\end{array}$ & .764 & .875 & .852 & $3.95(1.13)$ \\
\hline 9. I think that I will need [target language] for my future career. & .565 & .786 & .767 & $3.55(1.25)$ \\
\hline 3. I feel [target language] is an important language in the world. & .568 & 678 & 687 & $4.07(1.03)$ \\
\hline \multicolumn{5}{|l|}{ Factor 6: Language requirement $($ Cronbach's alpha $=.76)$} \\
\hline $\begin{array}{l}\text { 14. My major, or minor requires me to take [target language] } \\
\text { courses. }\end{array}$ & 616 & .858 & .791 & $2.63(1.70)$ \\
\hline 13. I need to fulfill a general foreign language requirement. & .616 & .845 & .765 & $2.65(1.55)$ \\
\hline \multicolumn{5}{|l|}{ Factor 7: Religion (Cronbach's alpha $=.81$ ) } \\
\hline $\begin{array}{l}\text { 11. Taking [target language] will help me in other religious } \\
\text { matters, such as a pilgrimage. }\end{array}$ & .697 & .910 & .855 & $1.65(1.02)$ \\
\hline $\begin{array}{l}\text { 10. Taking [target language] will help me on a mission or to } \\
\text { preach my religious beliefs to people who speak the language }\end{array}$ & 697 & .905 & .857 & $2.00(1.33)$ \\
\hline
\end{tabular}
preach my religious beliefs to people who speak the language.

Note. The words [target language] in the questionnaire were changed to languages such as 'Japanese', 'Portuguese', etc. for participants who study different languages.

Factor 2, learners' interest in culture, travel, and people, consisted of four items associated with attitudes towards having direct contact with L2 speakers, traveling to their countries, and appreciating their culture. Dörnyei (2005) stressed that this integrative motivational factor is seen as one of the most important motivational factors affecting language acquisition. Gardner (1985) also claimed that attitudes towards the L2 and its community is a key factor of L2 motivational construct after a review of studies conducted in diverse contexts. The three items in Factor 3, interest in contemporary cultural media, represented the appreciation of 
contemporary cultural products through media in L2, such as TV programs, films, and pop music. Dörnyei (2005) pointed out that this factor was often found in foreign language learning environments (e.g. foreign language classrooms) where L2 is taught as a school subject and direct contact with L2 community may not be possible. Dörnyei (2005) stated that this factor plays an important role in introducing the L2 community and shaping learners' attitudes towards the L2.

Factor 4, milieu, had three items referring to the influence of family and peers of learners. Studies (Dörnyei, 2001; Gardner, Masgoret, \& Tremblay, 1999; Spolsky, 2000) have shown that milieu is an important constituent of motivational construct and is related to learners' linguistic self-confidence, attitudes towards the learning situation, and learning efforts. Factor 5, instrumentality, included three items related to perceived usefulness and importance of L2 in learners' careers. It is one of the two major motivational orientations identified in Gardner's (1985) model.

Two items loaded in Factor 6, language requirement, addressed motivation to fulfill the academic degree requirement. This motivational factor is a type of extrinsic motive referred as Ought-to Self by Dörnyei (2005). Dörnyei (2005) explained that when learners see the learning of L2 as a basic educational requirement, they may not necessarily be motivated to take the language course due to personal preferences. The learners merely comply with requirements to avoid the negative consequences of not being able to receive a degree. Factor 7 , religion, contained two items related to religious motives in learning L2. Although religion is rarely discussed in motivation models and studies, the researchers in this study think that it can be explained by the motivation component, Ideal L2 Self, labeled by Dörnyei (2005). The Ideal L2 Self of the learners who scored high on the religion factor may feel a sense of growth and accomplishment when they use the L2 to be involved in religious matters.

MANOVA - The results of the MANOVA test indicated that the independent variables, gender and languages being learned, were not significant. In other words, whether a participant was female or male and whether the participant was studying a commonly or less commonly taught language, had little or no influence on their motivational construct. However, the results demonstrated that the independent variable, major, had a significant effect on the motivational constructs: $F(14,184)=2.083, p<.001, \eta 2=.155$; Power $=.952$. The results illustrated that the independent variable, religion, also had a significant effect on the motivational constructs: $F(14,184)=2.763, p<.001, \eta 2=.174$, Power $=.991$. Moreover, the results showed a significant interactive effect between major and religion, $F(28,333)=1.717, p<.01, \eta 2=.114$, Power $=.980$. The tests of between-subjects effects (See Table 3) revealed that the participants' major had a significant effect on Factor 6, the participants' religion had significant effects on Factors 3 and 7, and the participants' major and religion had an interactive effect on Factor 6.

\section{Table 3}

Multivariate analysis of variance: Between-subjects effects

\begin{tabular}{llcccc}
\hline Between-subjects effects & F & df & Sig. & Partial Eta Squared & Observed Power \\
\hline $\begin{array}{l}\text { Major } \\
\text { Factor 6: language requirement }\end{array}$ & 9.678 & 2 & .000 & .165 & .979 \\
\hline $\begin{array}{l}\text { Religion } \\
\text { Factor 3: interest in contemporary cultural products }\end{array}$ & & & & & .043 \\
\hline Religion & 2 & .021 & .076 & .708 \\
Factor 7: religion & 12.067 & & .000 & .198 & .994 \\
\hline $\begin{array}{l}\text { Major \& Religion } \\
\text { Factor 6: language requirement }\end{array}$ & 2.955 & 4 & .021 & .108 & .773 \\
\hline
\end{tabular}

The result of Bonferroni post hoc test on the variable, major, revealed that there was a significant difference between the participants who majored in Liberal Arts and in other majors on Factor 6. Participants who majored in Liberal Arts were more likely to take the foreign language courses in order to fulfill language requirements than participants who majored in other disciplines. The results of the post hoc test on the variable, religion 
showed that there was a significant difference between the LDS and the non-religious group on Factor 3. The LDS group was less likely to take the foreign language courses due to interest in contemporary cultural media than the non-religious group. In addition, the test found that there was a significant difference between all three sub-groups in the variable, religion, on Factor 7. The LDS participants were most likely to take the foreign language courses due to religious reasons followed by the other religions group and the not religious group.

Upon examination of the interactive effects of major and religion on Factor 6, language requirement (See Table 4), it was observed that the LDS participants in all three categories of majors were most likely to study L2 due to language requirement compared to the non-LDS groups. A close look at the LDS learners in the three different major groups revealed that the LDS participants who were in the 'other majors' category were most likely to study L2 for language requirement followed by LDS Business and LDS Liberal Arts majors. On the other hand, low means were found in all three categories of majors in the non-religious group, which indicated that language requirement was least likely the reason the non-religious group study L2.

\section{Table 4}

Between subjects interactive effects on Factor 6

\begin{tabular}{llll}
\hline Major & Religion & M & SD \\
\hline Business & LDS & 2.52 & 1.49 \\
& Other Religions & 1.65 & 1.25 \\
& Not Religious & 1.00 & 0.00 \\
\hline Liberal Arts & LDS & 2.36 & 1.10 \\
& Other Religions & 1.85 & 0.98 \\
& Not Religious & 1.07 & 0.25 \\
\hline Other Majors & LDS & 2.66 & 0.81 \\
& Other Religions & 1.21 & 0.45 \\
& Not Religious & 1.11 & 0.47 \\
\hline
\end{tabular}

Multiple regression - The multiple regression result showed that $\mathrm{R}=.70[\mathrm{~F}(7)=17.69, \mathrm{p}<.000]$ indicating a significant moderate positive relationship between the predictor and criterion variables. The R-square value indicated that about $50 \%$ of the variance in learners' interest in continuing foreign language learning was explained by Factors 1 and 2 . The $B$ values indicated the relative influence of the motivational factors; that is, Factor 2, learners' interest in culture, travel, and people $(\beta=.36)$ has the greatest influence on whether or not participants decided to continue the language study in the future, followed by Factor 1, positive learning attitudes/experience and intended efforts $(\beta=.34)$.

\section{Discussion and implications}

This study found the following motivational factors in the sample population of 130 first-year foreign language learners: positive learning attitudes/experience and intended efforts, interest in culture, travel, and people, interest in contemporary cultural media, milieu, instrumentality, language requirement, and religion. All motivational factors, except religion, found in this study are aligned with the major motivational dimensions identified in Gardner's (1985) and Dörnyei's (2005) studies. For example, unlike some of the studies (Sung \& Padilla, 1998; Wen, 2011) which found integrative and instrumental motivational factors merged into one factor, the results of this study showed that the two motivational components, instrumentality and interest in culture, travel, and people (integrative motivation), were loaded onto two different factors. This result is aligned with Gardner's (1985) motivation framework, which treats instrumental and integrative motivation orientations as separate factors. Wen (2011) explained that a reason the two motivational factors may merge into one could be attributed to learners' learning environments.

Wen (2011) elaborated that in an environment where L2 culture and speakers are not directly accessible (e.g. foreign language classroom), integrative motivation may become non-significant and be integrated into instrumental motivation. This reasoning may be true in certain study contexts such as Wen's (2011), but it is 
untrue in the current study context. Other reasons such as social and psychological factors may explain why the two motivational orientations merge or separate in different study contexts (Ely, 1986). With respect to the rarely identified motivational factor, religion, the results of this study showed that religion proved to be a significant motivational factor in the current study context. This significant result, and the fact that there is a lack of studies on religion and motivation, imply that the role of religion should be accounted for and looked into in future motivation studies, especially in a study context with a dense religious population.

This study found significant effects of major, religion, and an interactive effect between major and religion, on motivation. The LDS group was found to be more likely to study L2 for religious reasons than the participants who had other or no religions. One implication of this finding is the effect of LDS religious belief on the motivations of the LDS group. A possible reason the LDS group had a strong religious motivation studying L2 could be attributed to the active missionary culture in LDS. It is estimated that more than one million missionaries have served on missions since LDS's funding in 1830 (Walch, 2007) with more than 65,000 full-time missionaries worldwide in 2013 (Monson, 2013). Missionaries are often assigned to serve overseas; hence, the knowledge of L2 would be necessary. It could be this strong desire of serving a mission or simply a general interest in spreading the LDS belief to people overseas which drives the LDS group to study L2.

A significant contrast was found between the LDS and the non-religious group in the motivational factor, language requirement. The LDS group, regardless of their majors, was most likely to study L2 to fulfill language requirement than other groups while the non-religious group was the group least likely to do so. A similar trend of studying L2 due to language requirement was found in the Liberal Arts majors. The researchers' understanding is that the major requirements of the Business as well as Liberal Arts majors in this study indicated one to three years of foreign language learning requirements. However, only the Liberal Arts majors tended to study a foreign language for their major requirements. If language requirement, a motivational factor not based on learners' preferences and choices, is a strong reason to study L2, learning results cannot be optimal. According to Baker (1992), integratively motivated learners are generally more successful than others. Hence, an implication of the finding is that language teachers should familiarize learners with L2 culture in language classrooms, which will help develop learners' positive outlook towards the L2 and eventually be more successful in language learning.

The LDS group, which scored high on religious reasons for studying L2, showed significantly less interest in contemporary cultural media than the non-religious group. This result could be explained by the influence of the LDS missionary policy, which prohibited any forms of entertainment while on a mission. The Church of Jesus Christ of Latter-day Saints (2006) stated in the missionary handbook, 'Do not watch television, go to movies, listen to the radio, or use the Internet (except to communicate with your family or your mission president or as otherwise authorized)' (p. 25). The purpose of these media restrictions is so that missionaries can 'keep their eyes single to the Lord and His work' (The Church of Jesus Christ of Latter-day Saints, 2006, p. 25). Although the LDS participants were not serving a mission at the time the study was conducted, the LDS church's negative perception about media, such as music could 'dull your spiritual sensitivity' (The Church of Jesus Christ of Latter-day Saints, 2006, p. 25), may have discouraged the LDS members' interest in contemporary cultural media in L2. This finding implies that although introducing L2 culture, especially contemporary cultural media, is crucial in increasing learners' integrative motivation, language teachers should also respect and be sensitive to learners' religious beliefs. When teaching and religious beliefs conflict, language teachers and learners need to find a common ground where both parties are comfortable learning and teaching in the classroom.

This study found that two motivational factors, learners' interest in culture, travel, and people, and positive learning attitudes/experience and intended efforts, predicted learners' interest in continuing foreign language learning. In other words, when the learners had positive attitudes towards L2 community, enjoyed the learning environment they were in, and made efforts to learn L2, the tendency that the learners desired to continue language study was high. This finding is similar to the results found in Wen's (2011) study which showed that positive learning attitudes/experience and intended efforts is a strong predictor for future L2 study. However, Wen (2011) found instrumentality while this study found integrative motivation, (learners' interest in culture, 
Motivation and learner variables: Group differences in college foreign language learners' motivations

travel, and people), to be another predictor for the desire for future L2 study. This difference in finding could be attributed to the merging of instrumental and integrative motivation items into a single instrumentality factor in Wen's (2011) study. At least half of the motivational items identified in the instrumental factor in Wen's (2011) study were integrative oriented, which speaks to the importance of integrativeness in learners' motivations. The fact that positive attitudes and experience, intended efforts, and interest in L2 culture are predictors for future L2 study implies that language teachers not only need to introduce L2 culture to cultivate a high integrative motivation of learners, they also need to create a challenging and meaningful learning environment which learners would enjoy being involved in. A teaching implication from this finding is designing activities which are interactive and suitable to learners' levels, and selecting themes which catch students' attention.

Limitations - First, this study, conducted in a dense LDS population, found religion as one of the motivational factors and as a significant variable in motivational differences among the participants. Although this study recognized that religion played a significant role in motivation in the LDS group, as there is a lack of literature in motivation and religion, future studies will be needed to confirm the findings of the current study. Second, future studies with different research methods such as interview and observation will aid the construction of more elaborate explanations on the reasons behind the motivational differences found between the LDS and other groups. Third, although the size of the sample in this quantitative study was sufficient to ensure reliable statistical results, larger numbers of samples with diverse backgrounds in distinct study contexts will be needed to help contribute to the L2 motivation literature.

\section{References}

Al-Bustan, S. A., \& Al-Bustan, L. (2009). Investigating students attitudes and preferences towards learning English at Kuwait university. College Student Journal, 43(2), 454-463.

Baker, C. (1992). Attitudes and language. Clevedon: Multilingual Matters.

Canham, M. (2005). Mormon portion of Utah population steadily shrinking. Retrieved August 15, 2013, from http://www.sltrib.com/ci_2886596

Csizér, K., \& Dörnyei, Z. (2005). Language learners' motivational profiles and their motivated learning behavior. Language Learning, 55(4), 613-659. http://dx.doi.org/10.1111/j.0023-8333.2005.00319.x

Csizér, K., \& Kormos, J. (2008). The relationship of intercultural contact and language learning motivation among Hungarian students of English and German. Journal of Multilingual and Multicultural Development, 29(1), 30-48. http://dx.doi.org/10.2167/jmmd557.0

Dörnyei, Z. (2001). Teaching and researching motivation. London: Longman.

Dörnyei, Z. (2005). The psychology of the language learner: Individual differences in second language acquisition. Mahwah: Lawrence Erlbaum.

Dörnyei, Z., \& Csizér, K. (1998). Ten commandments for motivating language learners: Results of an empirical study. Language Teaching Research, 2, 203-229.

Dörnyei, Z., \& Otto, I. (1998). Motivation in action: A process model of L2 motivation. Working Papers in Applied Linguistics, 4, 43-69.

Dörnyei, Z., Csizér, K., \& Németh, N. (2006). Motivation, language attitudes, and globalization: A Hungarian perspective. Clevedon: Multilingual Matters.

Ely, C. M. (1986). Language learning motivation: A descriptive and causal analysis. The Modern Language Journal, 70, 28-35. http://dx.doi.org/10.1111/j.1540-4781.1986.tb05240.x

Furman, N., Goldberg, D., \& Lusin, N. (2010). Enrollments in languages other than English in United States institutions of higher education. Retrieved August 15, 2013, from http://www.mla.org/pdf/2009_enrollment_survey.pdf

Gardner, R., \& Lambert, W. (1972). Attitudes and motivation in second-language learning. Rowley: Newbury House.

Gardner, R. C. (1985). Social psychology and second language learning: The role of attitudes and motivation. London: Edward Arnold Publishers. 
Sung, K.-Y. \& Tsai, H.-M.

Gardner, R. C., \& Lalonde, R. N. (1985). Second language acquisition: A social psychological perspective. Retrieved August 15, 2013, from http://files.eric.ed.gov/fulltext/ED262624.pdf

Gardner, R. C., Masgoret, A. M., \& Tremblay, P. F. (1999). Home background characteristics and second language learning. Journal of Language and Social Psychology, 18, 419-437. http://dx.doi.org/10.1177/0261927X99018004004

Geisherik, A. (2004). The role of motivation among Heritage and non-heritage learners of Russian. Canadian Slavonic Papers, 46(1/2), 9-22.

George, D., \& Mallery, P. (2005). SPSS for windows step by step: A simple guide and reference 12.0 update. Boston: Person Education.

Ghazvini, S. D., \& Khajehpour, M. (2011). Attitudes and motivation in learning English as a second language in high school students. Procedia Social and Behavioral Sciences, 15, 1209-1213. http://dx.doi.org/10.1016/j.sbspro.2011.03.264

Gholam-Reza, K., Babak, M., \& Reza, G. S. (2013). Motivational changes of learners in a traditional context of English education: A case study of high school students in Iran. International Journal of Research Studies in Language Learning, 2(1), 3-16.

Henry, A. (2010). Contexts of possibility in simultaneous language learning: Using the L2 Motivational Self System to assess the impact of global English. Journal of Multilingual and Multicultural Development, 31(2), 149-162. http://dx.doi.org/10.1080/01434630903471439

Higgins, E. T. (1987). Self-discrepancy: A theory relating self and affect. Psychological Review, 94, 319-340. http://dx.doi.org/10.1037/0033-295X.94.3.319

Larson-Hall, J., \& Dewey, D. (2012). An examination of the effects of input, aptitude, and motivation on the language proficiency of missionaries learning Japanese as a second language. In L. Hansen (Ed.), Second language acquisition abroad: The LDS missionary experience (pp. 51-88). Philadelphia: John Benjamins Publishing Company.

Monson, T. (2013). Welcome to conference. Retrieved August 14, 2013, from http://www.lds.org/liahona/2013/05/welcome-to-conference

Mori, S., \& Gobel, P. (2006). Motivation and gender in the Japanese EFL classroom. System, 34, 194-210. http://dx.doi.org/10.1016/j.system.2005.11.002

Polat, N. (2011). Gender and age differences in motivation and L2 accent attainment: An investigation of young Kurdish learners of Turkish. Language Learning Journal, 39, 19-41. http://dx.doi.org/10.1080/09571730903545251

Spolsky, B. (2000). Language motivation revisited. Applied Linguistics, 21, 157-169. http://dx.doi.org/10.1093/applin/21.2.157

Sung, H., \& Padilla, A. (1998). Student motivation, parental attitudes, and involvement in the learning of Asian languages in elementary and secondary schools. The Modern Language Journal, 82(2), 205-216. http://dx.doi.org/10.1111/j.1540-4781.1998.tb01193.x

The Church of Jesus Christ of Latter-day Saints (2006). Missionary handbook. Retrieved August 15, 2013, from https://www.lds.org/bc/content/ldsorg/topics/missionary/MissionaryHandbook2006Navigate.pdf

Tong, F., \& Shi, Q. (2012). Chinese-English bilingual education in China: A case study of college science majors. International Journal of Bilingual Education and Bilingualism, 15(2), 165-182. http://dx.doi.org/10.1080/13670050.2011.607921

Walch, T. (2007). One million missionaries for LDS church - so far. Retrieved August 16, 2013, from http://www.deseretnews.com/article/680194052/1-million-missionaries-for-LDS-Church--so-far.html?p $\mathrm{g}=$ all

Wen, X. (2011). Chinese language learning motivation: A comparative study of heritage and non-heritage learners. Heritage Language Journal, 8(3), 41-66.

Williams, M., Burden, R., \& Lanvers, U. (2002). 'French is the language of love and stuff': Student perceptions of issues related to motivation in learning a foreign language. British Research Journal, 28(4), 503-508. http://dx.doi.org/10.1080/0141192022000005805 